\title{
Recent Advances in the Imaging Diagnosis of Hepatocellular Carcinoma: Value of Gadoxetic Acid-Enhanced MRI
}

\author{
Ijin Joo a, beong Min Lee ${ }^{a}, b, c$ \\ aDepartment of Radiology, Seoul National University Hospital, bepartment of Radiology, Seoul \\ National University College of Medicine, 'Institute of Radiation Medicine, Seoul National University \\ Medical Research Center, Seoul, Republic of Korea
}

\section{Key Words}

Diagnosis · Gadoxetic acid · Hepatocellular carcinoma - Liver · Magnetic resonance imaging

\begin{abstract}
Magnetic resonance imaging (MRI) using gadolinium ethoxybenzyl diethylenetriamine pentaacetic acid (Gd-EOB-DPTA), or gadoxetic acid for short, is a hepatocyte-specific contrast agent which is now increasingly used for the detection and characterization of focal hepatic lesions, particularly in patients at high-risk of developing hepatocellular carcinomas (HCC). In fact, several recent guidelines now recognize gadoxetic acid-enhanced MRI (Gd-EOB-MRI) as the primary diagnostic imaging modality for the noninvasive diagnosis of HCC, although it must be noted that several major guidelines still include only extracellular contrast mediaenhanced computed tomography and MRI. The primary merits of Gd-EOB-MRI lie in the fact that it can provide not only dynamic imaging, but also hepatobiliary phase (HBP) imaging which can lead to high lesion-to-liver contrast and give additional information regarding hepatocyte uptake via organic anion transporting polypeptides. This, in turn, allows higher sensitivity in detecting small HCCs and helps provide additional information regarding the multistep process of hepatocarcinogenesis. Indeed, many recent studies have investigated the diagnostic value of Gd-EOB-MRI for early HCCs as well as its role as a potential imaging biomarker in predicting outcome. We herein review the recent advances in the imaging diagnosis of HCCs focusing on the applications of Gd-EOB-MRI and the challenging issues that remain.




\section{Introduction}

Recently, magnetic resonance imaging (MRI) using gadolinium ethoxybenzyl diethylenetriamine pentaacetic acid (Gd-EOB-DTPA; Primovist@, Bayer Healthcare, Berlin, Germany), or gadoxetic acid for short, has been increasingly used to evaluate hepatic focal lesions including hepatocellular carcinomas (HCCs) [1]. Gd-EOB-DTPA has dual properties which include its distribution in the extracellular space, with approximately $50 \%$ of the administered dose actively taken up by hepatocytes via the organic anion transporting polypeptide 8 (OATP8) and excreted into the bile duct via the multidrug resistance protein 2 (MRP2), and the other $50 \%$ eliminated by renal excretion [2]. Therefore, Gd-EOB-DTPA-enhanced MRI (Gd-EOB-MRI) can provide not only information about the vascular phases, but also additional information regarding the hepatobiliary biliary phase (HBP) [3]. Whereas normal hepatic parenchyma progressively enhances due to the hepatocyte uptake of contrast media, most HCCs appear as hypointense nodules on HBP. Therefore, improved lesion-to-liver contrast can be obtained leading to higher sensitivity [4]. As studies have shown that the early detection of HCCs followed by prompt treatment can significantly improve outcome, the higher sensitivity of Gd-EOB-MRI in the detection of small HCCs can have great clinical value $[5,6]$.

At present, HCCs can be noninvasively diagnosed using typical imaging features of arterial enhancement followed by washout on the portal venous phase (PVP) and/or delayed phase (DP), without requirement of histologic confirmation followed by treatment $[7,8]$. Although several previous guidelines have recommended that the enhancement pattern should be assessed using extracellular contrast media (ECCM)-enhanced multiphasic computed tomography (CT) and MRI [7, 9], other recent guidelines have suggested Gd-EOB-MRI as one of the diagnostic tests for the noninvasive diagnosis of HCC [10-13]. Indeed, there is cumulative evidence of the value of Gd-EOB-MRI for the detection of small HCCs [14], and for the differentiation between HCCs and other hepatic lesions or hypervascular pseudolesions [15-17]. Furthermore, there is an emerging issue regarding the value of HBP imaging of GdEOB-MRI for the evaluation of multistep hepatocarcinogenesis and for predicting the prognosis of HCCs after surgery or radiofrequency ablation [18-23]. Multistep hepatocarcinogenesis can be characterized by its hemodynamic changes. The net effect of arterial supply initially decreases and then progressively increases, and there is a decrease in the expression of OATP8, a transporter responsible for the hepatocyte uptake of Gd-EOB-DTPA [1]. Therefore, borderline nodules can manifest as non-hypervascular HBP hypointense nodules while most progressed HCCs usually appear as hypervascular HBP hypointense nodules [1, 24].

In this review, we will discuss the latest topics in the imaging diagnosis of HCCs using Gd-EOB-MRI. Specifically, we will address the emerging role of Gd-EOB-MRI in the current practice guidelines for the noninvasive diagnosis of HCC, in the detection and diagnosis of small HCCs, and in the differentiation of HCCs from other hepatic focal lesions. In addition, pathological features and prognoses of non-hypervascular HBP hypointense nodules as well as the value of the HBP signal intensity of HCCs as a potential imaging biomarker will be covered.

\section{Gadoxetic Acid-Enhanced MRI in the Current Practice Guidelines for the Diagnosis of HCC}

Most major guidelines on the management of HCCs have, until now, recommended fourphase multi-detector row CT and/or contrast-enhanced MRI using ECCM as standard imaging modalities for the noninvasive diagnosis of HCC. This is based on the typical dynamic 
enhancement pattern of arterial enhancement and washout on the portal/delayed phase in patients with liver cirrhosis or chronic liver disease [7, 25]. However, the latest guidelines including those of the Japan Society of Hepatology (JSH) [10], the Korean Liver Cancer Study Group (KLCSG) and the National Cancer Center (NCC) [11], and the Liver Imaging-Reporting and Data System (LI-RADS) [12,13] have incorporated Gd-EOB-MRI into their diagnostic algorithms for HCC. According to the updated 2014 JSH guidelines, a noninvasive diagnosis of HCC can be made using Gd-EOB-MRI if a mass shows: 1) arterial hypervascularity and venous washout, or 2) arterial hypervascularity without venous washout, but with hypointensity on the HBP. Hemangioma must be excluded, which may show pseudo-washout on the transitional phase (TP: the late dynamic phase imaging obtained between PVP and HBP, usually 3-minute delayed scan) and hypointensity on the HBP using other sequences or imaging modalities [26]. In addition, for a hypovascular mass showing hypointensity on the HBP, contrast-enhanced ultrasonography using Sonazoid® (perfluorobutane) is recommended. If the mass shows hypervascularity and/or a defect in the Kupffer phase, HCC can be diagnosed [26]. The 2014 KLCSG-NCC guidelines include a 3-minute delayed scan of Gd-EOB-MRI to determine whether a hypervascular mass shows a "washout" appearance or not, although hypointensity on the HBP is not permissible as an alternative to washout [11]. Finally, the latest 2014 LIRADS guidelines also introduced its recommendation for the use of Gd-EOB-MRI to evaluate the dynamic enhancement pattern of hepatic nodules for the diagnosis of HCCs. It has differences from the JSH or KLCSG-NCC guidelines, including 1) "washout" appearance should be described on the PVP and 2) hypointensity on the HBP is regarded as one of the ancillary features favoring malignancy [13]. These differences in the included phase(s) for assessing "washout" between guidelines may have been derived from the different preferences for either higher sensitivity or higher specificity of a Gd-EOB-MRI diagnosis of HCC. As an example, when hypointensity on the TP and/or HBP is used as an alternative to "washout", the sensitivity for the diagnosis of HCC is increased, which may be appropriate in situations in which a high detection rate is preferred [27-30] (fig. 1). To the contrary, if a specific diagnosis of HCC is preferred, "washout" should be determined on the PVP alone because malignant lesions other than HCCs, such as intrahepatic cholangiocarcinomas (ICCs) as well as some benign lesions such as hemangioma, can show hypointensity on the TP and/or HBP [27, 31, 32] (figs. 1 and 2). Therefore, current practice guidelines for the use of Gd-EOB-MRI in the noninvasive diagnosis of HCC should be prospectively validated to provide confirmatory evidence of the diagnostic roles of this imaging technique.

\section{Small HCC}

Small HCCs usually refer to nodules $2 \mathrm{~cm}$ or smaller in diameter [33]. Early detection and subsequent treatment of this size-based subgroup of HCCs are critical in clinical practice, as patients with small HCCs show better prognosis after surgical resection or local ablation than those with large HCCs [5]. However, the imaging diagnosis of small HCCs has been a challenging issue in the aspect of both sensitivity and specificity because they are small, often poorly demarcated [34], and have a substantial overlap of imaging features with other benign or premalignant lesions [4] (figs. 3 and 4). These atypical imaging features of small HCCs may be explained by the histologic features of small HCCs. Small HCCs can be divided into two clinicopathological groups, either early HCCs or progressed HCCs [35]. Early HCCs are those in the incipient stage of HCC development whose histologic features are often difficult to distinguish from that of high-grade dysplastic nodules (DNs). The presence of stromal invasion in early HCCs can be a key to their differentiation. They consist of well-differentiated tumor cells, 


\section{Liver Cancer}

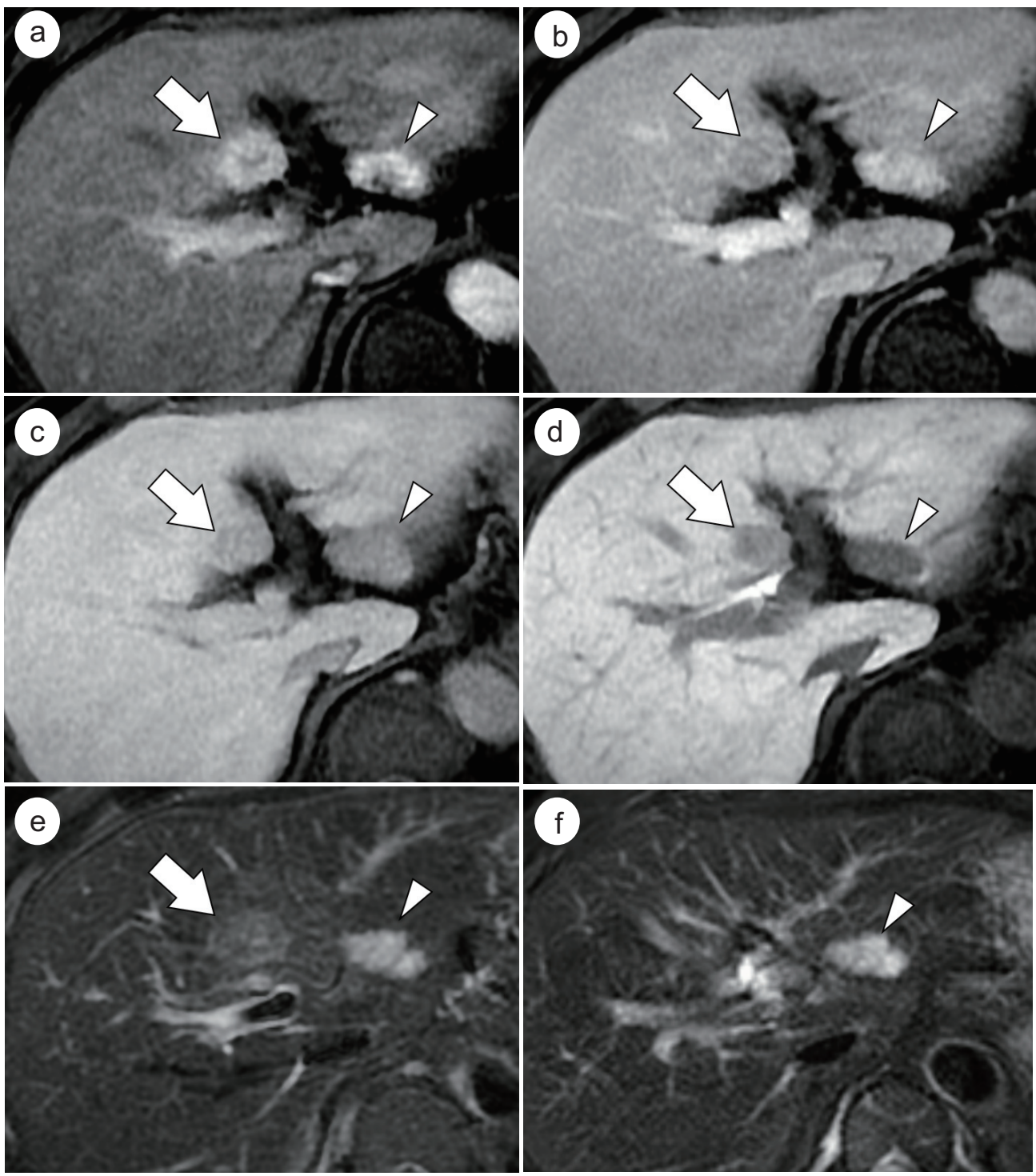

Fig. 1. HCC and hemangioma in a 63-year-old male patient with chronic hepatitis B virus infection. On Gd-EOB-MRI, a histopathologically confirmed HCC (arrows) in segment 4 of the liver shows enhancement on the HAP image (a), hypointensity on the PVP (b), TP (c), and HBP images (d), and intermediate hyperintensity on T2-weighted image (e). Different criteria for "washout" of current guidelines including "washout on the PVP" and "washout on the PVP and/or TP" can correctly diagnose this lesion in segment 4 as an HCC. Another hepatic nodule (arrowheads) in segment 2 of the liver shows arterial enhancement (a), persistent enhancement on the PVP (b), and hypointensity on the TP (c) and HBP images (d). As it shows a bright hyperintensity on T2-weighted image (e), and no interval change at 1-year follow-up after resection of the HCC in segment 4 (f), we can diagnose the lesion in segment 2 as a hemangioma. If hypointensity on the TP (pseudo-washout) (c) and/or HBP images (d) is used as an alternative to "washout", it would lead to an incorrect diagnosis of this hemangioma as an HCC.

which grow by replacing the hepatic parenchyma resulting in a vaguely nodular appearance with an indistinct margin [36]. On the other hand, small and progressed HCCs usually consist of moderately-differentiated components, and show an expansile growth resulting in a distinct nodular appearance surrounded by a tumor capsule [36]. 

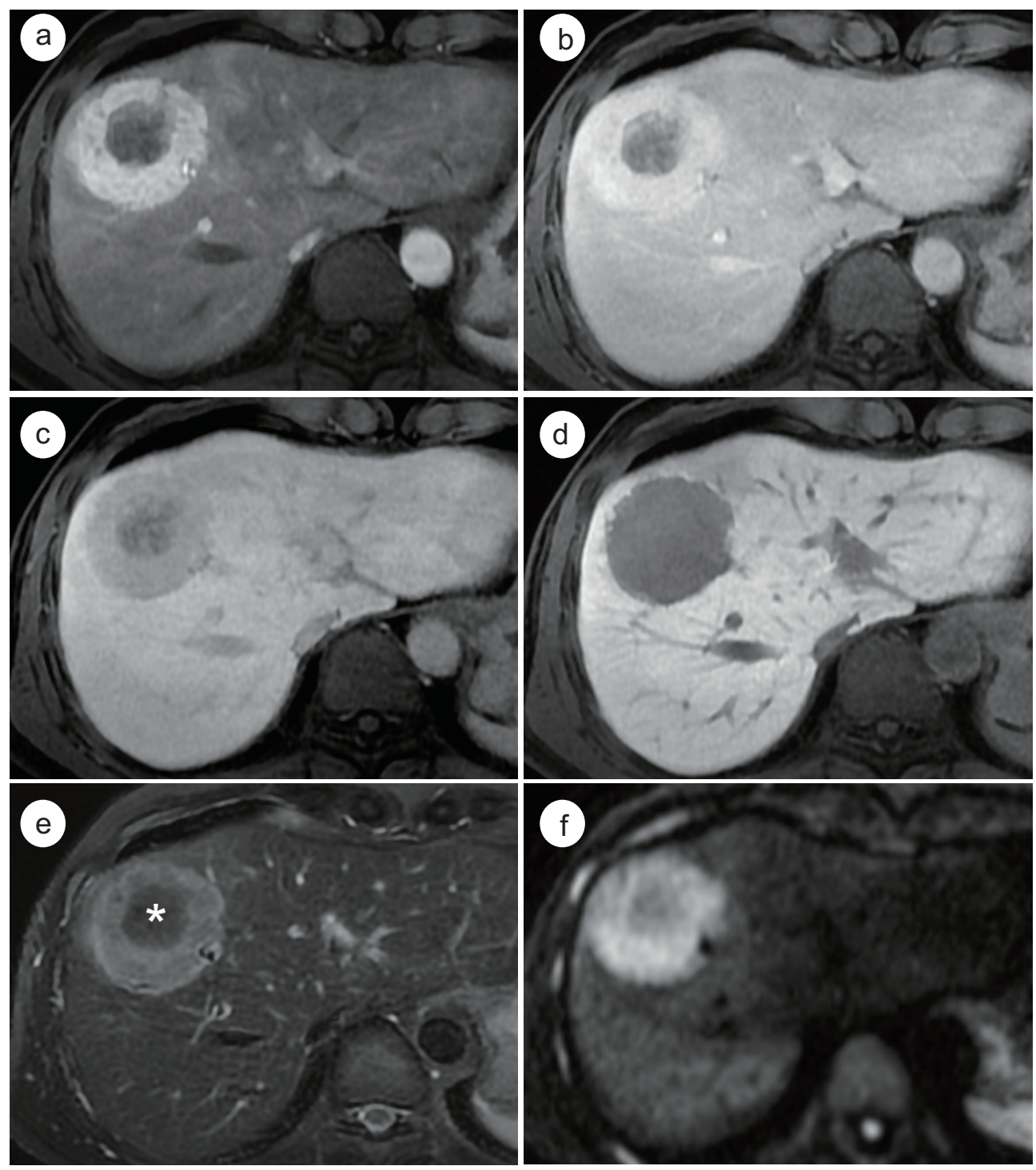

Fig. 2. Mass-forming type ICC which mimics the enhancement pattern of HCC on Gd-EOB-MRI in a 49-year-old male with alcoholic liver disease. A round mass which is located in segment 4 and 8 of the liver (a) shows arterial enhancement in the peripheral portion of the mass. The arterially-enhancing portion of the mass shows persistent enhancement on the PVP (b), but hypointensity on the TP (c) and HBP (d). Note the progressive enhancement of the central portion of the mass (a-c). On T2-weighted image, the peripheral portion of the mass (e) shows hyperintensity whereas the central portion $\left({ }^{*}\right)$ shows hypointensity due to the abundant fibrous stroma. On diffusion-weighted image (b value $=800 \mathrm{sec} / \mathrm{mm}^{2}$ ), the mass (f) demonstrates a target appearance. Histopathologic examination confirmed this tumor as cholangiocarcinoma.

For the detection of small HCCs, the diagnostic performances of CT and MRI have been reported to be lower compared to that for large HCCs [37-39]. According to the results of a recent meta-analysis, the per-lesion sensitivity estimates of CT and MRI were shown to be significantly lower for subcentimeter HCCs (31\% and 48\%, respectively) than for large HCCs ( $82 \%$ and $88 \%$, respectively) in patients with chronic liver disease [14]. Gd-EOB-MRI, which is an increasingly used imaging modality in patients at high-risk for developing HCCs, has the potential to improve sensitivity, mainly due to the high intrinsic soft-tissue contrast ability 


\section{Liver \\ Cancer}
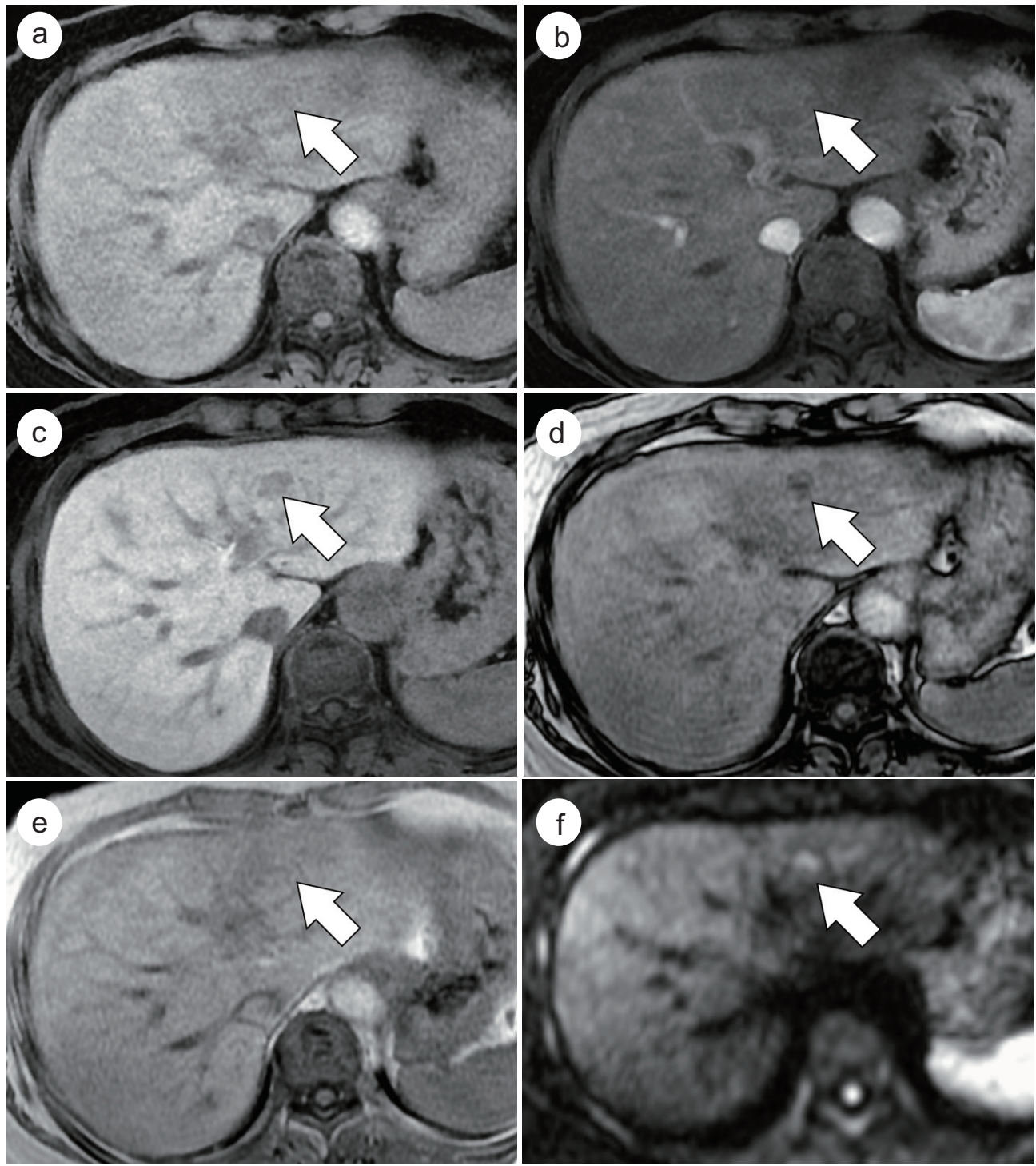

Fig. 3. Histopathologically-confirmed well-differentiated HCC in a 57-year-old female with chronic hepatitis B virus infection. Precontrast T1-weighted image demonstrates a $1.3 \mathrm{~cm}$ hypointense nodule (a) (arrow) in the left lateral segment of the liver. On the HAP image (b), subtle enhancement is noted in the hepatic nodule (arrow). The nodule (arrows) shows hypointensity on the HBP image (c), and signal drop on opposed-phase imaging (d) compared with that of in-phase imaging (e), indicative of intratumoral fat. On diffusion-weighted image ( $\mathrm{b}$ value $=800 \mathrm{sec} / \mathrm{mm}^{2}$ ), the nodule (f) demonstrates hyperintensity.

of MRI as well as tissue-specific HBP images in which most HCCs are seen as hypointense lesions compared with the surrounding hepatic parenchyma [6]. Accordingly, Gd-EOB-MRI leads to the additional detection of HCCs in patients who were initially diagnosed as having single-nodular HCC on dynamic CT. This may therefore reduce the risk of disease recurrence and improve overall survival after curative treatment [40]. Gd-EOB-MRI has shown superior performance compared with those of CT or ECCM-enhanced MRI in detecting small HCCs [41-44]. This is particularly relevant in the detection of additional HCCs for patients with lesions within the scope of the Milan criteria [45], and in the detection of recurrent HCCs for patients who have undergone curative resection for HCCs [46]. Furthermore, several studies have shown that the addition of hypointensity on the TP or HBP to the noninvasive 

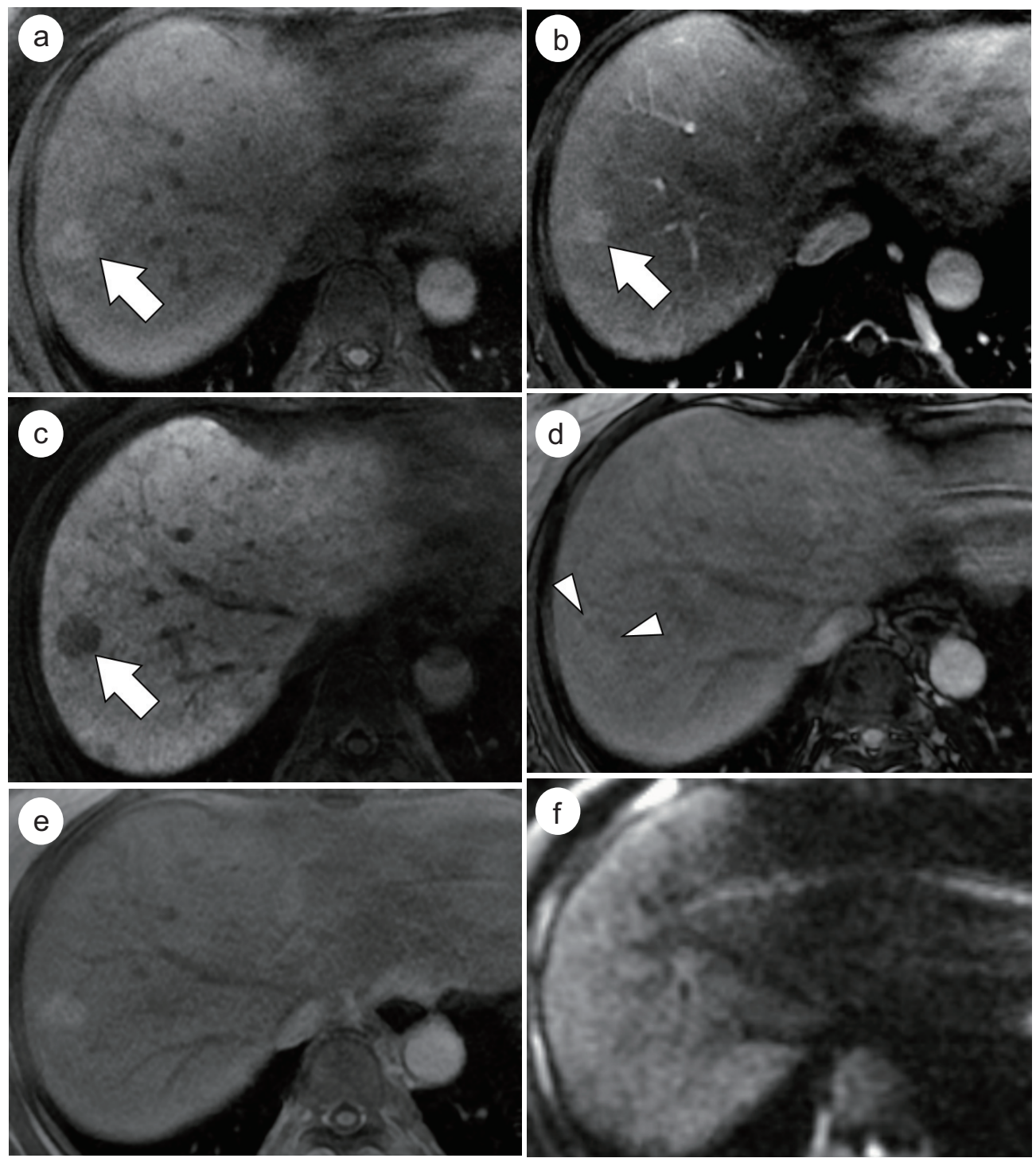

Fig. 4. Histopathologically-confirmed DN in a 55-year-old female with liver cirrhosis. A $2 \mathrm{~cm}$ nodule (arrows) in segment 8 of the liver shows hyperintensity on precontrast T1-weighted image (a), and no definite enhancement on the HAP image (b). On the HBP imaging (c), the nodule demonstrates hypointensity. On opposed-phase imaging (d), there are foci with decreased signal intensity compared with in-phase imaging (e), which suggest intratumoral fat component. On diffusion-weighted image (b value $=800 \mathrm{sec}$ / $\mathrm{mm}^{2}$ ), the nodule (f) shows isointensity.

diagnostic criteria may increase the diagnostic performance of Gd-EOB-MRI for small HCCs including subcentimeter lesions. However, there have been concerns regarding the lowering of specificity caused by difficulty in observing the enhancement pattern or signal intensity on T2-weighted imaging of subcentimeter sized, non-HCC lesions [27, 29, 30, 47]. Moreover, it has been shown that a combination of Gd-EOB-MRI and diffusion-weighted imaging (DWI) provides even higher diagnostic sensitivity in the detection of small HCCs than Gd-EOB-MRI or DWI alone $[48,49]$.

At present, for small hepatic nodules with typical enhancement patterns, some current guidelines allow the noninvasive diagnosis of HCCs for 1-2 cm nodules or regardless of their size, with or without the use of tumor markers and interval size changes; other guidelines do 
not allow the diagnosis of HCCs until a nodule reaches a certain size [10-12, 25, 50, 51]. The benefits of permitting a noninvasive diagnosis of small HCCs followed by treatment should be validated with respect to clinical outcome, medical costs, and selection of liver transplant candidates with HCC. However, reflecting the similarity of their histologic characteristics, the imaging features of small HCCs and DNs have a substantial overlap making differentiation difficult. In the cirrhotic liver, atypical enhancement patterns of small HCCs are not uncommon $[29,52]$, and it has been shown that in such circumstances, atypical enhancement patterns may be either early HCCs or non-malignant nodules [53]. Differentiation using GdEOB-MRI between HCCs and benign cirrhotic nodules will be discussed in the following section.

Imaging-based identification of high-risk small nodules is also important [54]. A study by Jang et al. reported that the presence of a typical enhancement pattern (arterial enhancement and hypointensity on PVP and/or TP) in subcentimeter HBP-hypointense nodules provides a high specificity for the prediction of progression to hypervascular HCCs [55]. In addition, Song et al. reported that a certain subgroup of subcentimeter nodules can progress to overt HCC at a high rate of $89.9 \%$ within 12 months when strict criteria were applied for selecting such nodules showing typical imaging features including typical enhancement pattern, hyperintensity on T2-weighted images, hyperintensity on DWI, and hypointensity on the HBP in patients with a known history of HCC [54].

\section{Differentiation of HCC from Other Hepatic Lesions}

\section{HCC vs. Other Hepatocellular Nodules}

Liver cirrhosis of any etiology is a major risk factor for developing HCCs, and approximately $80-90 \%$ of HCCs develop in patients with cirrhosis [56]. However, the imaging diagnosis of HCCs in the cirrhotic liver is often challenging as the liver may contain various kinds of hepatocellular nodules ranging from benign nodules to overt HCCs, which thereby reflects the multistep process of hepatocarcinogenesis. Such lesions also have a substantial overlap in pathologic features as well as imaging features [1] (figs. 3 and 4). Since OATP8 expression decreases during hepatocarcinogenesis, which results in hypointensity on the HBP of Gd-EOB-MRI [57], the signal intensity of this phase is helpful for the differentiation of HCCs from DNs and/or benign cirrhotic nodules $[42,58]$. In one study by Lee et al., they reported that hypointensity on HBP imaging and hyperintensity on DWI suggested well-differentiated HCCs rather than benign cirrhotic nodules [15]. Furthermore, Chou et al. showed that the addition of hypointensity on HBP imaging to the dynamic study of Gd-EOB-MRI provided better diagnostic performance in the differentiation of HCCs from DNs compared to the dynamic study alone [59]. However, Saito et al. reported that there were no significant differences in the enhancement ratio and the contrast-to-noise ratio in the HBP between HCCs and DNs [60]. This discrepancy may be explained by the spectrum of DNs and HCCs and their spectrum of signal intensities on the HBP. Inchingolo et al. showed that the signal intensity on DWI and HBP was useful in the differentiation between HCCs and DNs, and between HCCs plus high-grade DNs and low-grade DNs [61]. For cirrhotic nodules with atypical vascular enhancement patterns, Golfieri et al. reported that hypointensity on the HBP was predictive of malignancy [62]. The clinical importance and interpretation of non-hypervascular HBP hypointense nodules will be discussed in further detail later in this article.

Hyperintensity on the HBP in hepatic tumors, in other words, increased uptake of GdEOB-DPTA, usually suggests benign hepatocellular lesions with functioning hepatocytes such as focal nodular hyperplasia (FNH) or FNH-like nodules and some hepatocellular ad- 

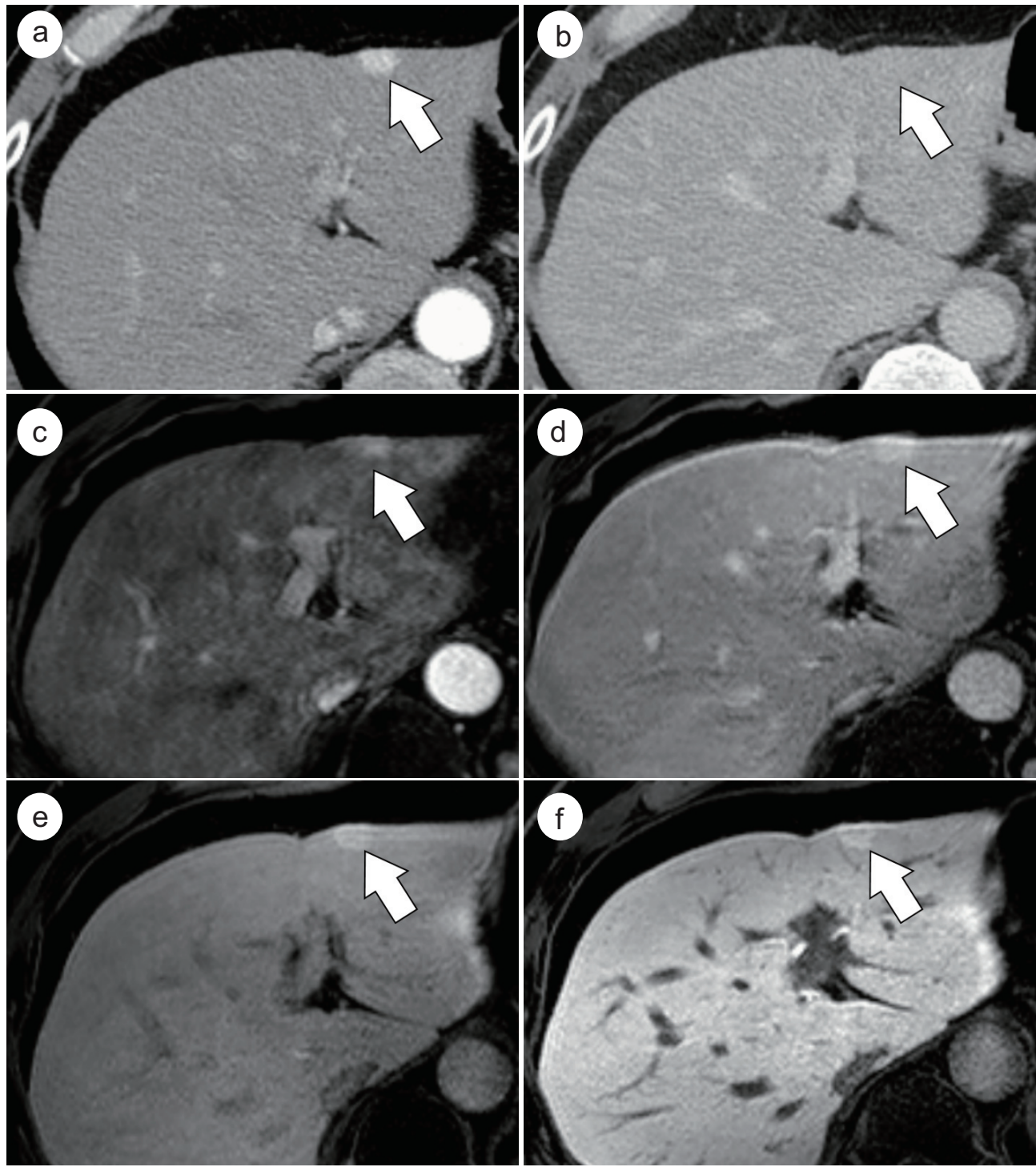

Fig. 5. Histopathologically-confirmed FNH-like nodule in a 65-year-old male with alcoholic liver cirrhosis. Dynamic contrast-enhanced CT images show a small nodule (arrows) with arterial enhancement (a) and no washout on DP imaging (b) in the left lateral segment of the liver. On Gd-EOB-MRI (c-f), the nodule (arrows) demonstrates hyperintensity on the HAP (c), PVP (d), TP (e), and HBP images (f).

enomas, whereas most malignant lesions including HCCs and metastases show hypointensity on the HBP [63]. Among the HBP hyperintense nodules, FNH in patients without chronic liver disease and FNH-like nodules in patients with chronic liver disease are the most common lesions whose typical enhancement features on Gd-EOB-MRI include i) hyperenhancement on the hepatic arterial phase (HAP), ii) no washout during PVP/TP, iii) hyperintensity in the area of hepatocyte hyperplasia and iv) central stellate hypointensity in the area of the fibrous scar on the HBP [64] (fig. 5). Although HCCs usually show hypointensity on HBP imaging, approximately $10-20 \%$ of HCCs show iso- to hyperintensity on such imaging due to the overexpression of OATP8 [22, 23], which can cause a diagnostic challenge in the interpretation of HBP hyperintense nodules. Suh et al. reported that several morphologic features on HBP including focal geographic defects of contrast uptake, which may reflect intratumoral necrosis 


\section{Liver Cancer}
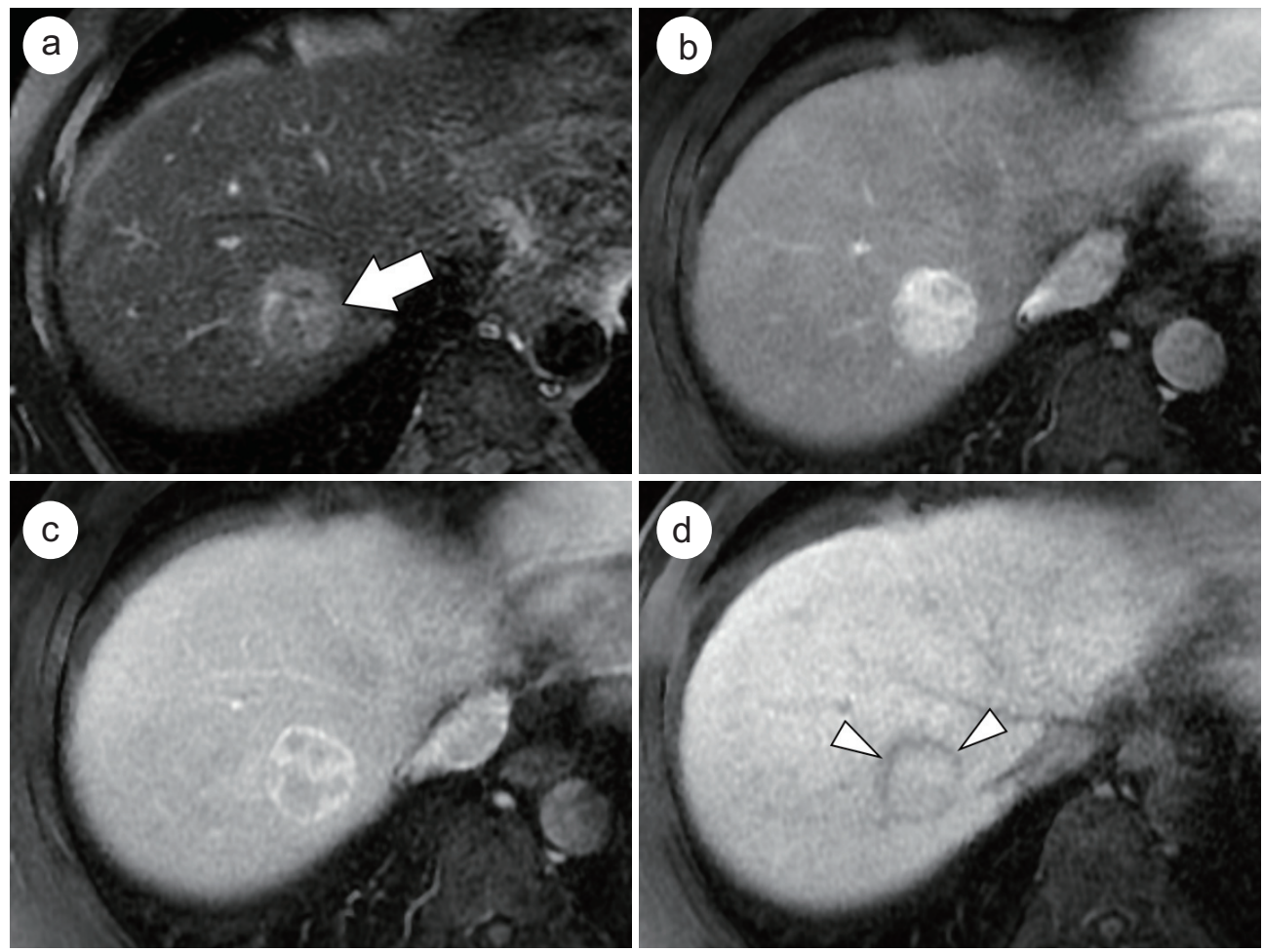

Fig. 6. HCC showing isointensity on the HBP in a 54-year-old male with chronic hepatitis B virus infection. T2-weighted image (a) shows a heterogeneously hyperintense mass (arrow) in segment 8 of the liver. The mass shows arterial enhancement (b), and heterogeneous washout on the PVP (c). On the HBP image (d), the mass shows isointensity with a hypointense rim (arrowheads) representing a peritumoral capsule. Histopathologic examination confirmed this mass as an HCC of Edmonson-Steiner grade II with trabecular and pseudoglandular patterns.

or heterogeneous histologic differentiation, and the presence of a hypointense rim, which represents a peritumoral capsule, were more common in HBP hyperintense HCCs than benign hyperintense lesions including FNHs and cirrhotic nodules [65] (fig. 6).

\section{HCC vs. Non-Hepatocellular Tumors}

ICC is the second most common primary malignancy in the liver, and its risk factors include chronic hepatitis and liver cirrhosis, which are also major risk factors for HCC [66]. Therefore, in the differentiation of hepatic nodules in high-risk patients, the possibility of ICCs should be ruled out [66]. Differentiating ICCs from HCCs with imaging studies is critical because their respective treatment strategies and prognoses are different $[67,68]$. On ECCM-enhanced imaging, ICCs typically show peripheral or weak enhancement on the HAP and centripetal or persistent enhancement on the PVP and DP [69, 70]. However, it has been reported that ICCs, particularly small ones, develop on the background of liver cirrhosis or chronic hepatitis showing arterial enhancement and/or a venous washout pattern more frequently than those in the normal liver [71, 72]. In addition, on Gd-EOB-MRI, different from ECCM-enhanced imaging, ICCs usually manifest as hypointensities on TP and HBP images due to the relatively high signal intensity of the surrounding parenchyma. Therefore, in hypervascular cases, ICCs often mimic HCCs based on Gd-EOB-MRI enhancement patterns $[32,73]$ (fig. 2). In this regard, several studies have reported that the imaging features of Gd-EOB-MRI may be helpful in the differentiation of these two disease entities. Features suggestive of ICCs rather than HCCs include i) the absence of fat and a tumor capsule [74], ii) 
central hypointensity on T2-weighted images [74], iii) a lower proportion showing arterial enhancement [75], iv) a target appearance on HBP images [16], and v) a target appearance on DWI [76].

Hepatic angiomyolipoma (AML) is a rare benign mesenchymal tumor which is composed of variable proportions of thick-walled vessels, smooth muscle cells, and adipose tissue [77]. As a result of the various percentages of mixed histologic components, hepatic AMLs can manifest with diverse imaging features [78]. Hepatic AMLs are sometimes misdiagnosed as HCCs because arterial enhancement and the presence of fat components are common in both lesions [78]. In addition, there are also lipid-poor AMLs which have no detectable fat components on imaging studies making the differentiation from other hypervascular tumors difficult $[77,79]$. According to a recent study which compared Gd-EOB-MRI features of lipid-poor AMLs and HCCs, both lesions showed similar dynamic enhancement patterns with arterial enhancement followed by hypointensity on the PVP or TP [80] (fig. 7). However, considering that AMLs do not have hepatocytes within the tumor whereas HCCs do contain hepatocytes with various degrees of malignant change, homogeneous hypointensity of the mass on HBP imaging and a lower value of relative signal intensity on HBP compared with the spleen may suggest hepatic AML rather than HCC [80] (fig. 7).

\section{HCC vs. Hypervascular Pseudolesions}

Hypervascular pseudolesions such as nontumorous arterioportal shunts (APS) are common mimickers of HCCs in patients with liver cirrhosis [81]. As liver cirrhosis progresses, APS via the trans-sinusoidal route can increasingly occur, which is thought to be related to cirrhosis-induced sinusoidal capillarization and obliteration of hepatic venules [82]. In addition, although APS are typically seen as subcapsular wedge- or triangular-shaped transient parenchymal enhancements on the HAP, APS in the cirrhotic liver tend to show a centrally located, round or oval appearance more frequently than those in the non-cirrhotic liver due to the architectural distortion of the background hepatic parenchyma, making the differentiation from HCCs difficult [83]. As a misdiagnosis of hypervascular pseudolesions as HCCs can lead to unnecessary treatment, the differentiation between these two disease entities is of importance in clinical practice. In this regard, hepatocyte-specific agents including Gd-EOBMRI can be helpful as hypervascular pseudolesions typically manifest isointensity on the HBP as they contain hepatocytes with intact function, which is different from HCCs [17] (fig. 8). However, Motosugi et al. reported that $15 \%$ of hypervascular pseudolesions showed relative hypointensity on the HBP compared with the surrounding liver parenchyma [84]. They suggested that imaging criteria such as low lesion-to-liver signal intensity ratio on the HBP and hyperintensity on DWI can be suggestive of HCCs rather than hypervascular pseudolesions in cases of hypervascular HBP hypointense nodules [84].

\section{Signal Intensity on the Hepatobiliary Phase: A Potential Imaging Biomarker of HCC}

Recently, increasing attention has focused on the signal intensity of HCCs on the HBP images as a potential imaging biomarker in patients with HCCs [18, 20, 57, 85]. HBP hyperintense HCCs have been reported to have histologic features related with favorable outcomes more frequently than HBP hypointense HCCs. As an example, hyperintense HCCs showed higher grades of tumor differentiation [20], a lower rate of microvascular invasion [20, 86], lower levels of expression of several kinds of poorer prognostic immunohistochemical markers including alpha-fetoprotein (AFP), protein induced by a vitamin K absence or antagonist- 


\section{Liver Cancer}
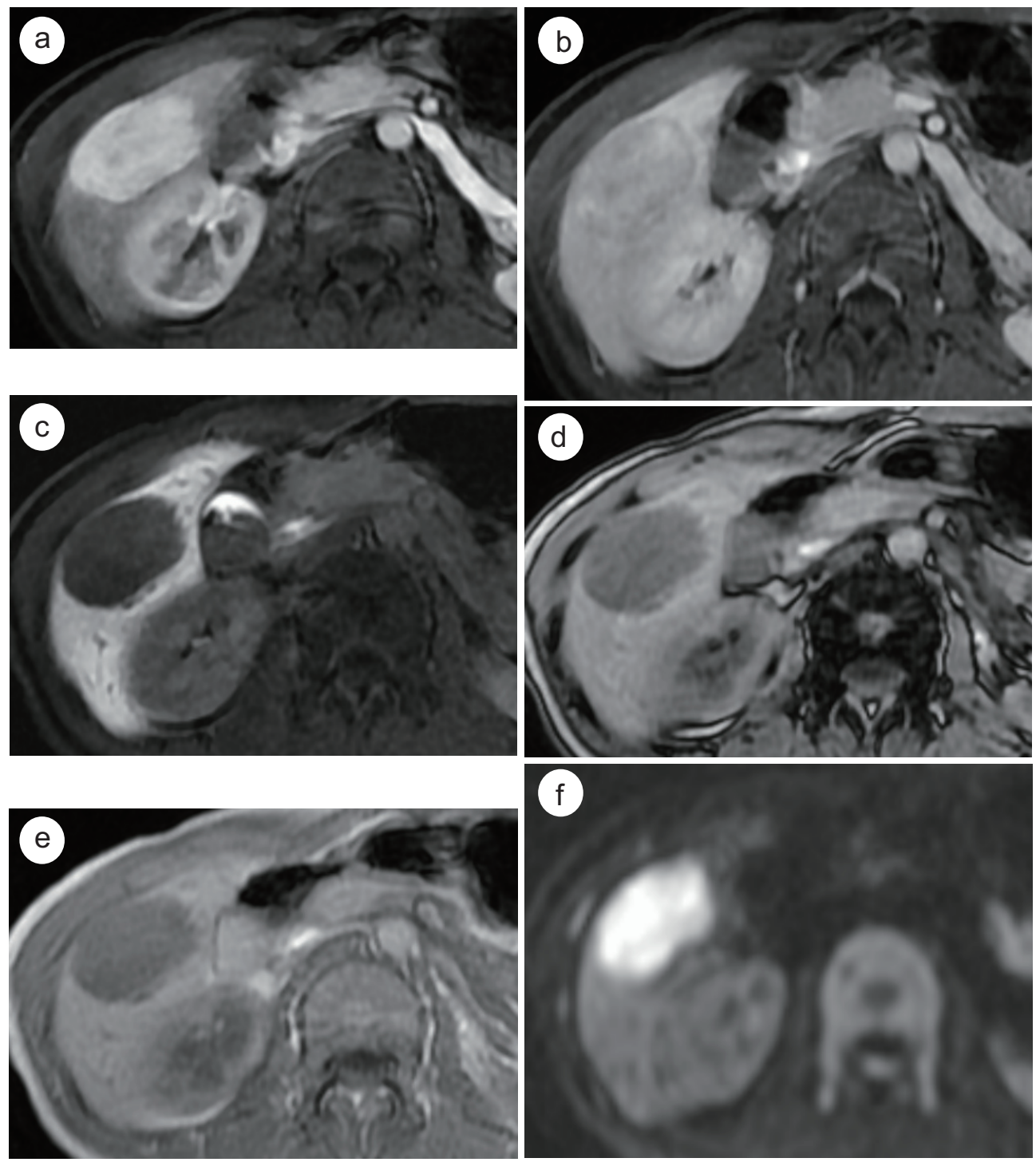

Fig. 7. Histopathologically-confirmed hepatic AML in a 33-year-old female without chronic liver disease. On Gd-EOB-MRI, a $5 \mathrm{~cm}$ oval mass in segment 5 of the liver shows homogeneous arterial enhancement (a), iso- to hypointensity on the PVP (b), and homogeneous hypointensity on the HBP images (c). No signal drop is noted in opposed-phase imaging (d) compared with in-phase imaging (e). Note the diffusion restriction of the hepatic mass (f) (DWI with b value of $800 \mathrm{sec} / \mathrm{mm}^{2}$ ).

II (PIVKA-II), epithelial cell adhesion molecule, cytokeratin 19 and glypican-3 [87]. However, the uptake of Gd-EOB-DTPA on HBP images is not always related with favorable prognostic markers. Fujita et al. showed that tumor size was larger and serum PIVKA-II was higher in patients with HCCs showing heterogeneous intensity on the HBP than in those with HCCs of homogeneous hypo- or hyperintensity [88].

In addition to the correlation of HBP signal intensity with histologic features, recent studies have demonstrated that outcome after treatment may be different according to HBP signal intensities of HCCs. Kitao et al. reported that patients with HBP-hyperintense HCCs showed significantly lower recurrence rates after surgery than those with HBP-hypointense HCCs [20]. Furthermore, Choi et al. revealed that HCCs with iso- to hyperintensity on HBP showed significantly longer time to tumor recurrence after surgery than those with hypoin- 

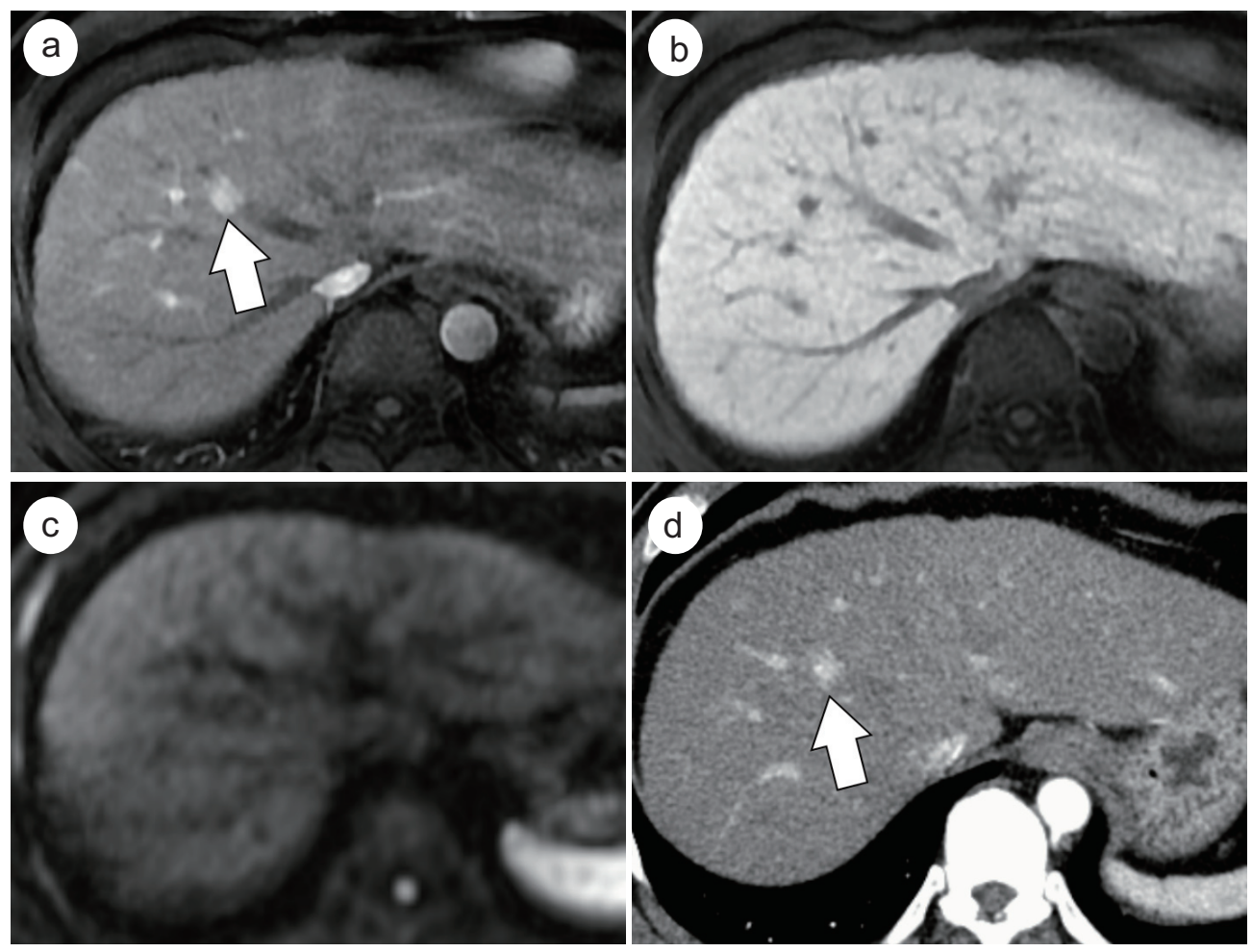

Fig. 8. Hypervascular pseudolesion in a 35-year-old male with liver cirrhosis. On the HAP image of GdEOB-MRI (a), a small arterially-enhancing nodular lesion (arrow) is seen in the central portion of the liver. The lesion is undetectable on the HBP image (b), and diffusion-weighted image (c). On the follow-up CT after 3 years, the arterially-enhancing lesion (d) shows no interval change.

tensity on HBP [85]. Fujita et al. also reported that signal homogeneity of HCCs on HBP was a favorable predictor of disease-free survival [88]. In addition, Yamashita et al. demonstrated that a noninvasive classification system according to HBP signal intensity and serum levels of AFP was useful in determining the patients' overall survival after surgical resection of earlystage HCCs [89]. Considering the usefulness of this information, further prospective studies with a large-scale cohort is warranted to validate the exact value of HBP signal intensities of HCCs as a prognostic marker in patients with HCCs.

The value of HBP imaging of Gd-EOB-MRI as a predictive biomarker can be attributed to the relationship between the uptake of Gd-EOB-DPTA on the HBP and the molecular characteristics of HCCs [57]. As mentioned earlier, most HCCs show hypointensity compared with the surrounding liver parenchyma on HBP images. However, approximately $10-20 \%$ of HCCs appear as iso- to hyperintense nodules on HBP images [22, 23] (fig. 6). Previous studies have revealed that this iso- or hyperintensity of HCCs on HBP may be related with the overexpression of transporters [90], and histological features of pseudoglandular proliferation [23]. OATP8 is a transporter responsible for the uptake of Gd-EOB-DTPA into hepatocytes and it usually decreases during hepatocarcinogenesis. However, it can be overexpressed in some HCCs, which has been speculated to reflect a different cell of origin or genetic alteration during hepatocarcinogenesis [57]. Kitao et al. reported that OATP8 expression in hypointense HCCs on HBP was lower while that in iso- or hyperintense HCCs on HBP was higher than the background liver. Immunohistochemistry also revealed a weak expression of OATP8 in hypointense HCCs compared to sustained expression in iso- or hyperintense HCCs [23]. In addition, overexpression of OATP8 in HCCs showed a strong association with the activation of Wnt/beta-catenin signaling pathways which has been reported to demonstrate a higher 
degree of tumor differentiation with frequent pseudoglandular proliferation [91, 92]. Pseudoglandular proliferation with bile plugs in HCCs would suggest the overproduction of bile and the secondary dilatation of the bile canaliculi. This histologic pattern of bile accumulation was reported to be more frequently observed in iso- or hyperintense HCCs than hypointense HCCs $[23,93]$. Not only the uptake into the cytoplasm via OATP8, but also the excretion into the bile canaliculi via MRP2 or back into the sinusoidal space via MRP3 can affect the degree of accumulation of Gd-EOB-DTPA in the tumor [90]. Tsuboyama et al. reported that increased MRP2 expression in the pseudoglands of HCCs, under the existence of OATP8, was associated with HBP hyperintense HCCs [93]. Similarly, Kimura et al. reported that HCCs with high expression levels of both OATP8 and MRP2 showed a higher relative enhancement ratio of HCC on HBP images than those with lower expression levels [19]. In addition, the expression of MRP3 in HCCs has been reported to be lower in hypointense HCCs than in isoor hyperintense HCCs [23].

\section{Non-Hypervascular HBP Hypointense Nodules}

During the process of hepatocarcinogenesis, unpaired arteries and sinusoidal capillarization gradually increase while the density of portal triads decreases [94]. Thus, the net effect of intratumoral arterial supply initially decreases during the early stage, and then increases leading to typical arterial enhancement of progressed HCCs [94]. In addition, as discussed above, OATP8 expression decreases progressively during hepatocarcinogenesis, and so, not only HCCs, but also earlier nodules including DNs and RNs can exhibit hypointensity on HBP images of Gd-EOB-MRI [57]. Therefore, considering the spectrum of the hemodynamic changes and OATP8 expression during hepatocarcinogenesis, borderline nodules can be seen as non-hypervascular HBP hypointense nodules [1,24]. Accordingly, common pathological diagnoses of non-hypervascular HBP hypointense nodules are high-grade DNs and early HCCs $[95,96]$. However, some low-grade DNs as well as large RNs can also manifest as non-hypervascular HBP hypointense nodules [97].

Non-hypervascular HBP hypointense nodules have gained increasing interest in recent years owing to their potential as borderline nodules to progress in the later steps of hepatocarcinogenesis, e.g., from DNs to HCCs, or early HCCs to progressed HCCs [98]. According to recent studies, this progression is not uncommon as approximately $30 \%$ of non-hypervascular HBP hypointense nodules become hypervascular HCCs during a follow-up period of one year $[95,99,100]$. In addition, approximately $30 \%$ of newly developed hypervascular HCCs may have the presence of non-hypervascular HBP hypointense nodules before hypervascularization in serial follow-up Gd-EOB-MRI [101]. Therefore, the identification of a highrisk subgroup of patients with non-hypervascular HBP hypointense nodules is important to predict tumor behavior and to determine more appropriate strategies for treatment and/or follow-up. Imaging features which are associated with interval progression to hypervascular HCCs include large (>9-10 mm diameter) nodule size on initial imaging [102, 103], rapid doubling time of the tumor volume [100,104], hyperintensity on T2-weighted images [100], hyper-intensity on pre-T1-weighted imaging [104], intratumoral fat components [104], and hyperintensity on DWI [99].

Regarding the prediction of outcome, there have been several reports showing that the presence of non-hypervascular HBP hypointense nodules can be a prognostic imaging biomarker $[20,21,92,105]$. According to these studies, in HCC surveillance, the presence of non-hypervascular HBP hypointense nodules in patients with chronic liver disease may be a high-risk factor for HCC development $[95,106]$. In addition, in patients with HCCs, the 
presence of concurrent non-hypervascular HBP hypointense nodules on pretreatment imaging can be an indicator of a higher likelihood of recurrence, particularly intrahepatic distant metastases, after hepatic resection or radiofrequency ablation [21, 105, 107] (fig. 9).

\section{Conclusion}

Gd-EOB-MRI, which can provide both vascular phase and HBP information, shows promise for the evaluation of focal liver lesions in patients at high-risk for HCC development. There is ample evidence, thus far, suggesting that Gd-EOB-MRI may be able to provide higher diagnostic performance owing to its higher sensitivity compared to ECCM-enhanced imaging in diagnosing small HCCs. Thus, several current guidelines now recommend Gd-EOB-MRI for the noninvasive diagnosis of HCCs, despite of the remaining, albeit considerable, concerns regarding its specificity. For the differentiation between HCCs and other hepatic focal lesions, a combination of information from HBP imaging and other sequences including dynamic phase images, T2-weighted imaging, and DWI is helpful. More importantly, reflecting the gradual decrease in the expression of OATP8 during hepatocarcinogenesis, borderline nodules can be seen as non-hypervascular HBP hypointense nodules, and the identification of high-risk nodules for progression to overt HCCs based on imaging features is critical for determining the appropriate patient management strategy. Furthermore, the signal intensity of HCCs on HBP imaging, which may reflect the molecular features including OATP8 expression, has been reported to be related to histologic characteristics and clinical outcomes in patients with HCCs.

To sum up, Gd-EOB-MRI, as a multiparametric imaging modality, provides not only high sensitivity, but also functional information, which can be useful in the diagnosis of HCCs as well as borderline nodules.

\section{Key Points}

- Several current guidelines for the noninvasive imaging diagnosis of HCC include Gd-EOBMRI for the evaluation of dynamic enhancement pattern, while they choose different phases for determining "washout" appearance.

- Due to its high soft-tissue contrast ability of MRI and tissue-specific HBP images, Gd-EOBMRI shows superior performance in the detection of small HCCs compared with CT or ECCMenhanced MRI.

- Signal intensity on the HBP images of Gd-EOB-MRI can be useful in the differentiation between HCCs and DNs and/or benign cirrhotic nodules, although there are substantial overlaps in the imaging features.

- In the background of cirrhosis of chronic hepatitis, hypervascular ICCs are not rare and they can mimic HCCs based on Gd-EOB-MRI enhancement pattern which should be interpreted with caution.

- For distinguishing hypervascular pseudolesions from HCCs, isointensity on HBP imaging is useful.

- HBP iso- or hyperintense HCCs may have favorable histologic features and clinical outcomes compared to hypointense HCCs.

- Common pathological diagnoses of non-hypervascular HBP hypointense nodules include high-grade DNs and early HCCs.

- Approximately $30 \%$ of non-hypervascular HBP hypointense nodules can progress to hypervascular HCCs. 


\section{Liver Cancer}
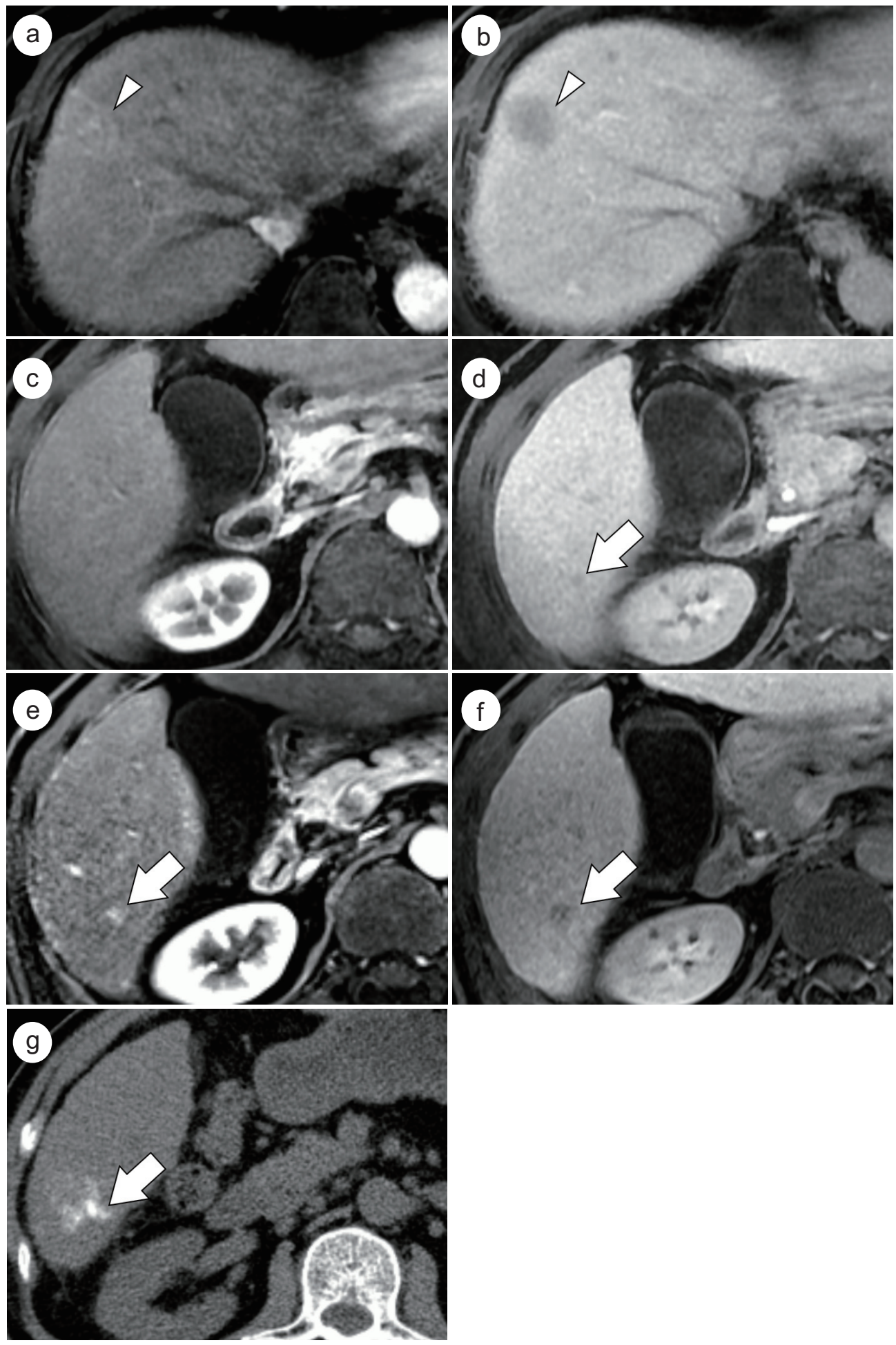

Fig. 9. Development of intrahepatic distant metastasis with a non-hypervascular HBP hypointense nodule after radiofrequency ablation (RFA) for HCC. A $2 \mathrm{~cm}$ HCC (arrowheads) in segment 8 of the liver demonstrates arterial enhancement (a) and hypointensity on the HBP image (b). There is another tiny lesion in segment 6 which shows no definite arterial enhancement (c) and hypointensity (arrow) on the HBP image (d). RFA was performed for the HCC in segment 8. Gd-EOB-MRI taken after 3 years shows interval development of arterial enhancement (e) and interval growth of the HBP hypointense nodule (arrows) (f). Note compact lipiodol uptake (arrow) in the nodule (g) after transarterial chemoembolization.

\section{KARGER}




\section{Disclosure Statement}

The authors declare no conflict of interest.

\section{References}

1 Choi JY, Lee JM, Sirlin CB: CT and MR imaging diagnosis and staging of hepatocellular carcinoma: part I. Development, growth, and spread: key pathologic and imaging aspects. Radiology 2014;272:635-654.

2 Van Beers BE, Pastor CM, Hussain HK: Primovist, Eovist: what to expect? J Hepatol 2012;57:421-429.

3 Kudo M: Will Gd-EOB-MRI change the diagnostic algorithm in hepatocellular carcinoma? Oncology 2010;78(Suppl 1):87-93.

4 Lee JM, Choi BI: Hepatocellular nodules in liver cirrhosis: MR evaluation. Abdom Imaging 2011;36:282-289.

5 de Lope CR, Tremosini S, Forner A, Reig M, Bruix J: Management of HCC. J Hepatol 2012;56(Suppl 1):S75S87.

6 Ahn SS, Kim MJ, Lim JS, Hong HS, Chung YE, Choi JY: Added value of gadoxetic acid-enhanced hepatobiliary phase MR imaging in the diagnosis of hepatocellular carcinoma. Radiology 2010;255:459-466.

7 Bota S, Piscaglia F, Marinelli S, Pecorelli A, Terzi E, Bolondi L: Comparison of International Guidelines for Noninvasive Diagnosis of Hepatocellular Carcinoma. Liver Cancer 2012;1(3-4):190-200.

8 Song do S, Bae SH: Changes of guidelines diagnosing hepatocellular carcinoma during the last ten-year period. Clinical and Molecular Hepatology 2012;18(3):258-267.

9 Kudo M, Izumi N, Kokudo N, Matsui O, Sakamoto M, Nakashima O, Kojiro M, Makuuchi M, HCC Expert Panel of Japan Society of Hepatology: Management of hepatocellular carcinoma in Japan: Consensus-Based Clinical Practice Guidelines proposed by the Japan Society of Hepatology (JSH) 2010 updated version. Dig Dis 2011;29:339-364.

10 Kudo M, Matsui O, Izumi N, Iijima H, Kadoya M, Imai Y, Liver Cancer Study Group of Japan: Surveillance and diagnostic algorithm for hepatocellular carcinoma proposed by the Liver Cancer Study Group of Japan: 2014 update. Oncology 2014;87(Suppl 1):7-21.

11 Lee JM, Park JW, Choi BI: 2014 KLCSG-NCC Korea Practice Guidelines for the management of hepatocellular carcinoma: HCC diagnostic algorithm. Dig Dis 2014;32:764-777.

12 Mitchell DG, Bruix J, Sherman M, Sirlin CB: LI-RADS (Liver Imaging Reporting and Data System): summary, discussion, and consensus of the LI-RADS Management Working Group and future directions. Hepatology 2015;61:1056-1065.

13 Hope TA, Fowler KJ, Sirlin CB, Costa EA, Yee J, Yeh BM, Heiken JP: Hepatobiliary agents and their role in LIRADS. Abdom Imaging 2015;40:613-625.

14 Lee YJ, Lee JM, Lee JS, Lee HY, Park BH, Kim YH, Han JK, Choi BI: Hepatocellular carcinoma: diagnostic performance of multidetector CT and MR imaging-a systematic review and meta-analysis. Radiology 2015;275:97-109.

15 Lee MH, Kim SH, Park MJ, Park CK, Rhim H: Gadoxetic acid-enhanced hepatobiliary phase MRI and high-bvalue diffusion-weighted imaging to distinguish well-differentiated hepatocellular carcinomas from benign nodules in patients with chronic liver disease. AJR Am J Roentgenol 2011;197:W868-875.

16 Chong YS, Kim YK, Lee MW, Kim SH, Lee WJ, Rhim HC, Lee SJ: Differentiating mass-forming intrahepatic cholangiocarcinoma from atypical hepatocellular carcinoma using gadoxetic acid-enhanced MRI. Clin Radiol 2012;67:766-773.

17 Sun HY, Lee JM, Shin CI, Lee DH, Moon SK, Kim KW, Han JK, Choi BI: Gadoxetic acid-enhanced magnetic resonance imaging for differentiating small hepatocellular carcinomas ( $<$ or $=2 \mathrm{~cm}$ in diameter) from arterial enhancing pseudolesions: special emphasis on hepatobiliary phase imaging. Invest Radiol 2010;45:96-103.

18 Choi JY, Lee JM, Sirlin CB: CT and MR imaging diagnosis and staging of hepatocellular carcinoma: part II Extracellular agents, hepatobiliary agents, and ancillary imaging features. Radiology 2014;273:30-50.

19 Kimura Y, Sato S, Hitomi E, Ohyama M, Adachi K, Inagaki Y, Yamakawa Y, Hirano A, Kawai H, Tsuchida K, Senoo K, Katsumi K, Joh T: Coexpression of organic anion-transporting polypeptides 1B3 and multidrugresistant proteins 2 increases the enhancement effect of gadolinium-ethoxybenzyl-diethylenetriamine pentaacetic acid on hepatocellular carcinoma in magnetic resonance imaging. Hepatology Research 2014;44(3):327-337.

20 Kitao A, Matsui O, Yoneda N, Kozaka K, Kobayashi S, Koda W, Gabata T, Yamashita T, Kaneko S, Nakanuma Y, Kita R, Arii S: Hypervascular hepatocellular carcinoma: correlation between biologic features and signal intensity on gadoxetic acid-enhanced MR images. Radiology 2012;265:780-789.

21 Lee DH, Lee JM, Lee JY, Kim SH, Kim JH, Yoon JH, Kim YJ, Lee JH, Yu SJ, Han JK, Choi BI: Non-hypervascular hepatobiliary phase hypointense nodules on gadoxetic acid-enhanced MRI: risk of HCC recurrence after radiofrequency ablation. J Hepatol 2015;62:1122-1130.

22 Narita M, Hatano E, Arizono S, Miyagawa-Hayashino A, Isoda H, Kitamura K, Taura K, Yasuchika K, Nitta T, Ikai I, Uemoto S: Expression of OATP1B3 determines uptake of Gd-EOB-DTPA in hepatocellular carcinoma. J Gastroenterol 2009;44:793-798.

23 Kitao A, Zen Y, Matsui O, Gabata T, Kobayashi S, Koda W, Kozaka K, Yoneda N, Yamashita T, Kaneko S, Nakanuma Y: Hepatocellular carcinoma: signal intensity at gadoxetic acid-enhanced MR Imaging-correlation with molecular transporters and histopathologic features. Radiology 2010;256:817-826. 
24 Kobayashi S, Matsui O, Gabata T, Koda W, Minami T, Ryu Y, Kozaka K, Kitao A: Relationship between signal intensity on hepatobiliary phase of gadolinium ethoxybenzyl diethylenetriaminepentaacetic acid (GdEOB-DTPA)-enhanced MR imaging and prognosis of borderline lesions of hepatocellular carcinoma. Eur J Radiol 2012;81:3002-3009.

25 Bruix J, Sherman M, American Association for the Study of Liver Diseases: Management of hepatocellular carcinoma: an update. Hepatology 2011;53:1020-1022.

26 Kudo M, Matsui O, Izumi N, Iijima H, Kadoya M, Imai Y, Okusaka T, Miyayama S, Tsuchiya K, Ueshima K: JSH Consensus-Based Clinical Practice Guidelines for the Management of Hepatocellular Carcinoma: 2014 Update by the Liver Cancer Study Group of Japan. Liver Cancer 2014;3(3-4):458-468.

27 Joo I, Lee JM, Lee DH, Jeon JH, Han JK, Choi BI: Noninvasive diagnosis of hepatocellular carcinoma on gadoxetic acid-enhanced MRI: can hypointensity on the hepatobiliary phase be used as an alternative to washout? Eur Radiol 2015 Mar 14. [Epub ahead of print].

28 Phongkitkarun S, Limsamutpetch K, Tannaphai P, Jatchavala J: Added value of hepatobiliary phase gadoxetic acid-enhanced MRI for diagnosing hepatocellular carcinoma in high-risk patients. World J Gastroenterol 2013;19:8357-8365.

29 Yu MH, Kim JH, Yoon JH, Kim HC, Chung JW, Han JK, Choi BI: Small $(\leq 1-\mathrm{cm})$ hepatocellular carcinoma: diagnostic performance and imaging features at gadoxetic acid-enhanced MR imaging. Radiology 2014;271:748-760.

30 Lee DH, Lee JM, Baek JH, Shin CI, Han JK, Choi BI: Diagnostic performance of gadoxetic acid-enhanced liver MR imaging in the detection of HCCs and allocation of transplant recipients on the basis of the Milan criteria and UNOS guidelines: correlation with histopathologic findings. Radiology 2015;274:149-160.

31 Doo KW, Lee CH, Choi JW, Lee J, Kim KA, Park CM: "Pseudo washout" sign in high-flow hepatic hemangioma on gadoxetic acid contrast-enhanced MRI mimicking hypervascular tumor. AJR Am J Roentgenol 2009;193:W490-496.

32 Péporté AR, Sommer WH, Nikolaou K, Reiser MF, Zech CJ: Imaging features of intrahepatic cholangiocarcinoma in Gd-EOB-DTPA-enhanced MRI. Eur J Radiol 2013;82:e101-e106.

33 Willatt JM, Hussain HK, Adusumilli S, Marrero JA: MR Imaging of hepatocellular carcinoma in the cirrhotic liver: challenges and controversies. Radiology 2008;247:311-330.

34 Nakashima O, Sugihara S, Kage M, Kojiro M: Pathomorphologic characteristics of small hepatocellular carcinoma: a special reference to small hepatocellular carcinoma with indistinct margins. Hepatology 1995;22:101-105.

35 The International Consensus Group for Hepatocellular Neoplasia: Pathologic diagnosis of early hepatocellular carcinoma: a report of the international consensus group for hepatocellular neoplasia. Hepatology 2009;49:658-664.

36 Roskams T, Kojiro M: Pathology of early hepatocellular carcinoma: conventional and molecular diagnosis. Semin Liver Dis 2010;30:17-25.

37 Forner A, Vilana R, Ayuso C, Bianchi L, Solé M, Ayuso JR, Boix L, Sala M, Varela M, Llovet JM, Brú C, Bruix J: Diagnosis of hepatic nodules $20 \mathrm{~mm}$ or smaller in cirrhosis: Prospective validation of the noninvasive diagnostic criteria for hepatocellular carcinoma. Hepatology 2008;47:97-104.

38 Krinsky GA, Lee VS, Theise ND, Weinreb JC, Morgan GR, Diflo T, John D, Teperman LW, Goldenberg AS: Transplantation for hepatocellular carcinoma and cirrhosis: sensitivity of magnetic resonance imaging. Liver Transpl 2002;8(12):1156-1164.

39 de Lédinghen V, Laharie D, Lecesne R, Le Bail B, Winnock M, Bernard PH, Saric J, Couzigou P, Balabaud C, Bioulac-Sage P, Drouillard J: Detection of nodules in liver cirrhosis: spiral computed tomography or magnetic resonance imaging? A prospective study of 88 nodules in 34 patients. Eur J Gastroenterol Hepatol 2002;14:159-165.

40 Kim HD, Lim YS, Han S, An J, Kim GA, Kim SY, Lee SJ, Won HJ, Byun JH: Evaluation of early-stage hepatocellular carcinoma by magnetic resonance imaging with gadoxetic Acid detects additional lesions and increases overall survival. Gastroenterology 2015;148:1371-1382.

41 Kim SH, Kim SH, Lee J, Kim MJ, Jeon YH, Park Y, Choi D, Lee WJ, Lim HK: Gadoxetic acid-enhanced MRI versus triple-phase MDCT for the preoperative detection of hepatocellular carcinoma. AJR Am J Roentgenol 2009;192:1675-1681.

42 Inoue T, Kudo M, Komuta M, Hayaishi S, Ueda T, Takita M, Kitai S, Hatanaka K, Yada N, Hagiwara S, Chung H, Sakurai T, Ueshima K, Sakamoto M, Maenishi O, Hyodo T, Okada M, Kumano S, Murakami T: Assessment of Gd-EOB-DTPA-enhanced MRI for HCC and dysplastic nodules and comparison of detection sensitivity versus MDCT. J Gastroenterol 2012;47:1036-1047.

43 Sano K, Ichikawa T, Motosugi U, Sou H, Muhi AM, Matsuda M, Nakano M, Sakamoto M, Nakazawa T, Asakawa M, Fujii H, Kitamura T, Enomoto N, Araki T: Imaging study of early hepatocellular carcinoma: usefulness of gadoxetic acid-enhanced MR imaging. Radiology 2011;261:834-844.

44 Park G, Kim YK, Kim CS, Yu HC, Hwang SB: Diagnostic efficacy of gadoxetic acid-enhanced MRI in the detection of hepatocellular carcinomas: comparison with gadopentetate dimeglumine. Br J Radiol 2010;83:1010-1016.

45 Cha DI, Lee MW, Kim YK, Kim SH, Park HJ, Rhim H, Lim HK: Assessing patients with hepatocellular carcinoma meeting the Milan criteria: Is liver 3 tesla MR with gadoxetic acid necessary in addition to liver CT? J Magn Reson Imaging 2014;39:842-852.

46 Kim KA, Kim MJ, Choi JY, Park MS, Lim JS, Chung YE, Kim KW: Detection of recurrent hepatocellular carcinoma on post-operative surveillance: comparison of MDCT and gadoxetic acid-enhanced MRI. Abdom Imaging 2014;39:291-299. 
47 Park VY, Choi JY, Chung YE, Kim H, Park MS, Lim JS, Kim KW, Kim MJ: Dynamic enhancement pattern of HCC smaller than $3 \mathrm{~cm}$ in diameter on gadoxetic acid-enhanced MRI: comparison with multiphasic MDCT. Liver International 2014;34(10):1593-1602.

48 Park MJ, Kim YK, Lee MW, Lee WJ, Kim YS, Kim SH, Choi D, Rhim H: Small hepatocellular carcinomas: improved sensitivity by combining gadoxetic acid-enhanced and diffusion-weighted MR imaging patterns. Radiology 2012;264:761-770.

49 Park MJ, Kim YK, Lee MH, Lee JH: Validation of diagnostic criteria using gadoxetic acid-enhanced and diffusion-weighted MR imaging for small hepatocellular carcinoma $(<=2.0 \mathrm{~cm})$ in patients with hepatitisinduced liver cirrhosis. Acta Radiol 2013;54:127-136.

50 Omata M, Lesmana LA, Tateishi R, Chen PJ, Lin SM, Yoshida H, Kudo M, Lee JM, Choi BI, Poon RT, Shiina S, Cheng AL, Jia JD, Obi S, Han KH, Jafri W, Chow P, Lim SG, Chawla YK, Budihusodo U, Gani RA, Lesmana CR, Putranto TA, Liaw YF, Sarin SK: Asian Pacific Association for the Study of the Liver consensus recommendations on hepatocellular carcinoma. Hepatology International 2010;4(2):439-474.

51 European Association For The Study Of The Liver European Organisation For Research And Treatment Of Cancer: EASL-EORTC clinical practice guidelines: management of hepatocellular carcinoma. J Hepatol 2012;56:908-943.

52 Yoon SH, Lee JM, So YH, Hong SH, Kim SJ, Han JK, Choi BI: Multiphasic MDCT enhancement pattern of hepatocellular carcinoma smaller than $3 \mathrm{~cm}$ in diameter: tumor size and cellular differentiation. AJR Am J Roentgenol 2009;193:W482-489.

53 Bolondi L, Gaiani S, Celli N, Golfieri R, Grigioni WF, Leoni S, Venturi AM, Piscaglia F: Characterization of small nodules in cirrhosis by assessment of vascularity: the problem of hypovascular hepatocellular carcinoma. Hepatology 2005;42:27-34.

54 Song KD, Kim SH, Lim HK, Jung SH, Sohn I, Kim HS: Subcentimeter hypervascular nodule with typical imaging findings of hepatocellular carcinoma in patients with history of hepatocellular carcinoma: natural course on serial gadoxetic acid-enhanced MRI and diffusion-weighted imaging. Eur Radiol 2015 Mar 4. [Epub ahead of print].

55 Jang KM, Kim SH, Kim YK, Choi D: Imaging features of subcentimeter hypointense nodules on gadoxetic acid-enhanced hepatobiliary phase MR imaging that progress to hypervascular hepatocellular carcinoma in patients with chronic liver disease. Acta Radiol 2015;56:526-535.

56 Fattovich G, Stroffolini T, Zagni I, Donato F: Hepatocellular carcinoma in cirrhosis: incidence and risk factors. Gastroenterology 2004;127(Suppl 1):S35-S50.

57 Kitao A, Matsui O, Yoneda N, Kozaka K, Shinmura R, Koda W, Kobayashi S, Gabata T, Zen Y, Yamashita T, Kaneko S, Nakanuma Y: The uptake transporter OATP8 expression decreases during multistep hepatocarcinogenesis: correlation with gadoxetic acid enhanced MR imaging. Eur Radiol 2011;21:2056-2066.

58 Ichikawa T, Sano K, Morisaka H: Diagnosis of Pathologically Early HCC with EOB-MRI: Experiences and Current Consensus. Liver Cancer 2014;3(2):97-107.

59 Chou CT, Chen YL, Su WW, Wu HK, Chen RC: Characterization of cirrhotic nodules with gadoxetic acidenhanced magnetic resonance imaging: the efficacy of hepatocyte-phase imaging. J Magn Reson Imaging 2010;32:895-902.

60 Saito K, Kotake F, Ito N, Ozuki T, Mikami R, Abe K, Shimazaki Y: Gd-EOB-DTPA enhanced MRI for hepatocellular carcinoma: quantitative evaluation of tumor enhancement in hepatobiliary phase. Magnetic resonance in medical sciences: MRMS 2005;4(1):1-9.

61 Inchingolo R, De Gaetano AM, Curione D, Ciresa M, Miele L, Pompili M, Vecchio FM, Giuliante F, Bonomo L: Role of diffusion-weighted imaging, apparent diffusion coefficient and correlation with hepatobiliary phase findings in the differentiation of hepatocellular carcinoma from dysplastic nodules in cirrhotic liver. Eur Radiol 2015;25:1087-1096.

62 Golfieri R, Grazioli L, Orlando E, Dormi A, Lucidi V, Corcioni B, Dettori E, Romanini L, Renzulli M: Which is the best MRI marker of malignancy for atypical cirrhotic nodules: hypointensity in hepatobiliary phase alone or combined with other features? Classification after Gd-EOB-DTPA administration. J Magn Reson Imaging 2012;36:648-657.

63 Kim MJ, Rhee HJ, Jeong HT: Hyperintense lesions on gadoxetate disodium-enhanced hepatobiliary phase imaging. AJR Am J Roentgenol 2012;199:W575-586.

64 Grieser C, Steffen IG, Seehofer D, Kramme IB, Uktolseya R, Scheurig-Muenkler C, Hamm B, Denecke T: Histopathologically confirmed focal nodular hyperplasia of the liver: gadoxetic acid-enhanced MRI characteristics. Magn Reson Imaging 2013;31:755-760.

65 Suh YJ, Kim MJ, Choi JY, Park YN, Park MS, Kim KW: Differentiation of hepatic hyperintense lesions seen on gadoxetic acid-enhanced hepatobiliary phase MRI. AJR Am J Roentgenol 2011;197:W44-52.

66 Razumilava N, Gores GJ: Cholangiocarcinoma. Lancet 2014;383:2168-2179.

67 Zhou XD, Tang ZY, Fan J, Zhou J, Wu ZQ, Qin LX, Ma ZC, Sun HC, Qiu SJ, Yu Y, Ren N, Ye QH, Wang L, Ye SL: Intrahepatic cholangiocarcinoma: report of 272 patients compared with 5,829 patients with hepatocellular carcinoma. J Cancer Res Clin Oncol 2009;135:1073-1080.

68 Lee JH, Chung GE, Yu SJ, Hwang SY, Kim JS, Kim HY, Yoon JH, Lee HS, Yi NJ, Suh KS, Lee KU, Jang JJ, Kim YJ: Long-term prognosis of combined hepatocellular and cholangiocarcinoma after curative resection comparison with hepatocellular carcinoma and cholangiocarcinoma. J Clin Gastroenterol 2011;45:69-75.

69 Zhang Y, Uchida M, Abe T, Nishimura H, Hayabuchi N, Nakashima Y: Intrahepatic peripheral cholangiocarcinoma: comparison of dynamic CT and dynamic MRI. J Comput Assist Tomogr 1999;23:670-677. 
70 Rimola J, Forner A, Reig M, Vilana R, de Lope CR, Ayuso C, Bruix J: Cholangiocarcinoma in cirrhosis: absence of contrast washout in delayed phases by magnetic resonance imaging avoids misdiagnosis of hepatocellular carcinoma. Hepatology 2009;50:791-798.

71 Kim SJ, Lee JM, Han JK, Kim KH, Lee JY, Choi BI: Peripheral mass-forming cholangiocarcinoma in cirrhotic liver. AJR Am J Roentgenol 2007;189:1428-1434.

72 Xu J, Igarashi S, Sasaki M, Matsubara T, Yoneda N, Kozaka K, Ikeda H, Kim J, Yu E, Matsui O, Nakanuma Y: Intrahepatic cholangiocarcinomas in cirrhosis are hypervascular in comparison with those in normal livers. Liver International 2012;32(7):1156-1164.

73 Kang Y, Lee JM, Kim SH, Han JK, Choi BI: Intrahepatic mass-forming cholangiocarcinoma: enhancement patterns on gadoxetic acid-enhanced MR images. Radiology 2012;264:751-760.

74 Asayama Y, Nishie A, Ishigami K, Ushijima Y, Takayama Y, Fujita N, Kubo Y, Aishima S, Shirabe K, Yoshiura T, Honda H: Distinguishing intrahepatic cholangiocarcinoma from poorly differentiated hepatocellular carcinoma using precontrast and gadoxetic acid-enhanced MRI. Diagnostic and interventional radiology 2015;21(2):96-104.

75 Park MJ, Kim YK, Park HJ, Hwang J, Lee WJ: Scirrhous hepatocellular carcinoma on gadoxetic acid-enhanced magnetic resonance imaging and diffusion-weighted imaging: emphasis on the differentiation of intrahepatic cholangiocarcinoma. J Comput Assist Tomogr 2013;37:872-881.

76 Park HJ, Kim YK, Park MJ, Lee WJ: Small intrahepatic mass-forming cholangiocarcinoma: target sign on diffusion-weighted imaging for differentiation from hepatocellular carcinoma. Abdom Imaging 2013;38:793-801.

77 Nonomura A, Enomoto Y, Takeda M, Takano M, Morita K, Kasai T: Angiomyolipoma of the liver: a reappraisal of morphological features and delineation of new characteristic histological features from the clinicopathological findings of 55 tumours in 47 patients. Histopathology 2012;61:863-880.

78 Wang SY, Kuai XP, Meng XX, Jia NY, Dong H: Comparison of MRI features for the differentiation of hepatic angiomyolipoma from fat-containing hepatocellular carcinoma. Abdom Imaging 2014;39:323-333.

79 Cai PQ, Wu YP, Xie CM, Zhang WD, Han R, Wu PH: Hepatic angiomyolipoma: CT and MR imaging findings with clinical-pathologic comparison. Abdom Imaging 2013;38:482-489.

80 Kim R, Lee JM, Joo I, Lee DH, Woo S, Han JK, Choi BI: Differentiation of lipid poor angiomyolipoma from hepatocellular carcinoma on gadoxetic acid-enhanced liver MR imaging. Abdom Imaging 2015;40:531-541.

81 Choi BI, Lee KH, Han JK, Lee JM: Hepatic arterioportal shunts: dynamic CT and MR features. Korean J Radiol 2002;3:1-15.

82 Bookstein JJ, Cho KJ, Davis GB, Dail D: Arterioportal communications: observations and hypotheses concerning transsinusoidal and transvasal types. Radiology 1982;142:581-590.

83 Ahn JH, Yu JS, Hwang SH, Chung JJ, Kim JH, Kim KW: Nontumorous arterioportal shunts in the liver: CT and MRI findings considering mechanisms and fate. Eur Radiol 2010;20:385-394.

84 Motosugi U, Ichikawa T, Sou H, Sano K, Tominaga L, Muhi A, Araki T: Distinguishing hypervascular pseudolesions of the liver from hypervascular hepatocellular carcinomas with gadoxetic acid-enhanced MR imaging. Radiology 2010;256:151-158.

85 Choi JW, Lee JM, Kim SJ, Yoon JH, Baek JH, Han JK, Choi BI: Hepatocellular carcinoma: imaging patterns on gadoxetic acid-enhanced MR Images and their value as an imaging biomarker. Radiology 2013;267:776786.

86 Kim JY, Kim MJ, Kim KA, Jeong HT, Park YN: Hyperintense HCC on hepatobiliary phase images of gadoxetic acid-enhanced MRI: correlation with clinical and pathological features. Eur J Radiol 2012;81:3877-3882.

87 Yoneda N, Matsui O, Kitao A, Kita R, Kozaka K, Koda W, Kobayashi S, Gabata T, Ikeda H, Nakanuma Y: Hypervascular hepatocellular carcinomas showing hy perintensity on hepatobiliary phase of gadoxetic acidenhanced magnetic resonance imaging: a possible subtype with mature hepatocyte nature. Jpn J Radiol. 2013;31(7):480-490.

88 Fujita N, Nishie A, Kubo Y, Asayama Y, Ushijima Y, Takayama Y, Moirta K, Shirabe K, Aishima S, Honda H: Hepatocellular carcinoma: clinical significance of signal heterogeneity in the hepatobiliary phase of gadoxetic acid-enhanced MR imaging. Eur Radiol 2015;25:211-220.

89 Yamashita T, Kitao A, Matsui O, Hayashi T, Nio K, Kondo M, Ohno N, Miyati T, Okada H, Yamashita T, Mizukoshi E, Honda M, Nakanuma Y, Takamura H, Ohta T, Nakamoto Y, Yamamoto M, Takayama T, Arii S, Wang X, Kaneko S: Gd-EOB-DTPA-enhanced magnetic resonance imaging and alpha-fetoprotein predict prognosis of early-stage hepatocellular carcinoma. Hepatology 2014;60:1674-1685.

90 Jeong WK, Kim YK, Song KD, Choi D, Lim HK: The MR imaging diagnosis of liver diseases using gadoxetic acid: emphasis on hepatobiliary phase. Clin Mol Hepatol. 2013;19(4):360-366.

91 Ueno A, Masugi Y, Yamazaki K, Komuta M, Effendi K, Tanami Y, Tsujikawa H, Tanimoto A, Okuda S, Itano O, Kitagawa Y, Kuribayashi S, Sakamoto M: OATP1B3 expression is strongly associated with Wnt/ $\beta$ catenin signalling and represents the transporter of gadoxetic acid in hepatocellular carcinoma. J Hepatol 2014;61:1080-1087.

92 Kitao A, Matsui O, Yoneda N, Kozaka K, Kobayashi S, Sanada J, Koda W, Minami T, Inoue D, Yoshida K, Yamashita T, Yamashita T, Kaneko S, Takamura H, Ohta T, Ikeda H, Nakanuma Y, Kita R, Gabata T: Hepatocellular Carcinoma with $\beta$-Catenin Mutation: Imaging and Pathologic Characteristics. Radiology 2015;275:708-717.

93 Tsuboyama T, Onishi H, Kim T, Akita H, Hori M, Tatsumi M, Nakamoto A, Nagano H, Matsuura N, Wakasa K, Tomoda K: Hepatocellular carcinoma: hepatocyte-selective enhancement at gadoxetic acid-enhanced MR imaging-correlation with expression of sinusoidal and canalicular transporters and bile accumulation. Radiology 2010;255:824-833. 
94 Matsui O, Kobayashi S, Sanada J, Kouda W, Ryu Y, Kozaka K, Kitao A, Nakamura K, Gabata T: Hepatocelluar nodules in liver cirrhosis: hemodynamic evaluation (angiography-assisted CT) with special reference to multi-step hepatocarcinogenesis. Abdom Imaging 2011;36:264-272.

95 Yoon JH, Lee JM, Yang HK, Lee KB, Jang JJ, Han JK, Choi BI: Non-hypervascular hypointense nodules $\geq 1 \mathrm{~cm}$ on the hepatobiliary phase of gadoxetic acid-enhanced magnetic resonance imaging in cirrhotic livers. Dig Dis 2014;32:678-689.

96 Bartolozzi C, Battaglia V, Bargellini I, Bozzi E, Campani D, Pollina LE, Filipponi F: Contrast-enhanced magnetic resonance imaging of 102 nodules in cirrhosis: correlation with histological findings on explanted livers. Abdom Imaging 2013;38:290-296.

97 Golfieri R, Renzulli M, Lucidi V, Corcioni B, Trevisani F, Bolondi L: Contribution of the hepatobiliary phase of Gd-EOB-DTPA-enhanced MRI to Dynamic MRI in the detection of hypovascular small $(\leq 2 \mathrm{~cm}) \mathrm{HCC}$ in cirrhosis. Eur Radiol 2011;21:1233-1242.

98 Kanefuji T, Takano T, Suda T, Akazawa K, Yokoo T, Kamimura H, Kamimura K, Tsuchiya A, Takamura M, Kawai H, Yamagiwa S, Aoyama H, Nomoto M, Terai S: Factors predicting aggressiveness of non-hypervascular hepatic nodules detected on hepatobiliary phase of gadolinium ethoxybenzyl diethylene-triaminepentaacetic-acid magnetic resonance imaging. World J Gastroenterol 2015;21:4583-4591.

99 Kim YK, Lee WJ, Park MJ, Kim SH, Rhim H, Choi D: Hypovascular hypointense nodules on hepatobiliary phase gadoxetic acid-enhanced MR images in patients with cirrhosis: potential of DW imaging in predicting progression to hypervascular HCC. Radiology 2012;265:104-114.

100 Hyodo T, Murakami T, Imai Y, Okada M, Hori M, Kagawa Y, Kogita S, Kumano S, Kudo M, Mochizuki T: Hypovascular nodules in patients with chronic liver disease: risk factors for development of hypervascular hepatocellular carcinoma. Radiology 2013;266:480-490.

101 Yamamoto A, Ito K, Tamada T, Higaki A, Kanki A, Sato T, Tanimoto D: Newly developed hypervascular hepatocellular carcinoma during follow-up periods in patients with chronic liver disease: observation in serial gadoxetic acid-enhanced MRI. AJR Am J Roentgenol 2013;200:1254-1260.

102 Takayama Y, Nishie A, Nakayama T, Asayama Y, Ishigami K, Kakihara D, Ushijima Y, Fujita N, Hirakawa M, Honda H: Hypovascular hepatic nodule showing hypointensity in the hepatobiliary phase of gadoxetic acidenhanced MRI in patients with chronic liver disease: prediction of malignant transformation. Eur J Radiol 2012;81:3072-3078.

103 Matsuda M, Tsuda T, Yoshioka S, Murata S, Tanaka H, Hirooka M, Hiasa Y, Mochizuki T: Incidence for progression of hypervascular HCC in hypovascular hepatic nodules showing hyperintensity on gadoxetic acidenhanced hepatobiliary phase in patients with chronic liver diseases. Jpn J Radiol. 2014;32(7):405-413.

104 Higaki A, Ito K, Tamada T, Teruki S, Yamamoto A, Higashi H, Kanki A, Sato T, Noda Y: High-risk nodules detected in the hepatobiliary phase of Gd-EOB-DTPA-enhanced MR imaging in cirrhosis or chronic hepatitis: incidence and predictive factors for hypervascular transformation, preliminary results. J Magn Reson Imaging 2013;37:1377-1383.

105 Toyoda H, Kumada T, Tada T, Sone Y, Maeda A, Kaneoka Y: Non-hypervascular hypointense nodules on GdEOB-DTPA-enhanced MRI as a predictor of outcomes for early-stage HCC. Hepatol Int 2015;9(1):84-92.

106 Ichikawa S, Ichikawa T, Motosugi U, Sano K, Morisaka H, Enomoto N, Matsuda M, Fujii H, Araki T: Presence of a hypovascular hepatic nodule showing hypointensity on hepatocyte-phase image is a risk factor for hypervascular hepatocellular carcinoma. J Magn Reson Imaging 2014;39:293-297.

107 Toyoda H, Kumada T, Tada T, Niinomi T, Ito T, Sone Y, Kaneoka Y, Maeda A: Non-hypervascular hypointense nodules detected by Gd-EOB-DTPA-enhanced MRI are a risk factor for recurrence of HCC after hepatectomy. J Hepatol 2013;58:1174-1180. 